\title{
Por um currículo plural na perspectiva do multiculturalismo
}

\author{
For a pluralistic curriculum in the perspective of multiculturalism
}

\begin{abstract}
Maria das Graças Gonçalves Vieira Guerra
Doutora em Educação pela Universidade Federal da Paraíba. Professora do Centro de Educação da Universidade Federal da Paraíba. Paraíba - PB - Brasil

gracinhavieira@yahoo.com.br

Iracema Campos Cusati

Doutora na área de Didática, Teorias de Ensino e Práticas Escolares pela Faculdade de Educação da Universidade de São Paulo. Professora do Colegiado de Matemática da Universidade de Pernambuco. Recife - PE - Brasil iracema.cusati@upe.br

Kleber Ferreira Costa Mestre em Linguagem e Ensino pela Universidade Federal de Campina Grande. Professor assistente da Universidade de Pernambuco. Recife - PE - Brasil

kf.costa1@hotmail.com
\end{abstract}

Resumo: O multiculturalismo, como corpo teórico e campo político, tem sido discutido intensamente nos debates atuais. Entretanto, esse termo, polissêmico na contemporaneidade, não pode ser considerado modismo e como tal é foco da problematização nesse artigo, por gerar preocupações pelas consequências à formação de professores e à educação de futuras gerações. Inserida num contexto sociocultural, a escola produz e/ou reproduz a exclusão de vários grupos sociais, gerando insucesso e evasão. Para tal, apoiados nas reflexões apresentadas pelos teóricos, discutimos questões do cenário das políticas educacionais em função da diversidade étnico-racial, da interculturalidade e do multiculturalismo na busca de compreensão de como esse cenário pode contribuir para uma prática docente compromissada com as demandas sociais. Em tempos de choques culturais, a educação e a formação de professores não cabem se furtar quanto ao multiculturalismo, pois é premente incrementar pesquisas comprometidas com a concretização de ideais multiculturais na formação de professores e no currículo.

Palavras-chave: Multiculturalismo. Currículo plural. Escola multicultural.

Abstract: Multiculturalism, as a theoretical body and political field, has been discussed intensively in the current debates. However, this term, which is polysemic in contemporary times, can't be considered a fad, and as such is the focus of the problematization in this article, because it raises concerns about the consequences of teacher training and education for future generations. Inserted in a sociocultural context, the school produces and / or reproduces the exclusion of several social groups, generating failure and avoidance. To that end, based on the reflections presented by the theorists, we discuss issues of the educational policy scenario in terms of ethnic-racial diversity, interculturality and multiculturalism in order to understand how this scenario can contribute to a teaching practice committed to social demands. In times of cultural clashes, education and teacher training can't be avoided as far as multiculturalism is concerned, since it is urgent to increase research committed to the achievement of multicultural ideals in teacher training and curriculum.

Keywords: Multiculturalism. Plural curriculum. Multicultural school. 


\section{Introdução}

O multiculturalismo, como corpo teórico e campo político, tem sido discutido e revisitado intensamente em grande parte dos debates na atualidade principalmente pela necessidade de compreendermos a sociedade como constituída de identidades plurais, com base na diversidade de raças, gênero, classe social, padrões culturais, linguísticos e outros marcadores identitários. O multiculturalismo constitui uma ruptura epistemológica com o projeto da modernidade, no qual se acreditava na homogeneidade e na evolução natural da humanidade rumo a um acúmulo de conhecimentos que levariam à construção universal do progresso. Opostamente, entendemos por multiculturalismo a abordagem que vai além da valorização da diversidade cultural em termos folclóricos, aquela que questiona a construção das diferenças e, por conseguinte, dos estereótipos e preconceitos contra aqueles percebidos como diferentes em sociedades desiguais e excludentes (CANEN; OLIVEIRA, 2002).

Uma educação multicultural insere-se em uma visão pós-moderna de sociedade, em que a diversidade, a descontinuidade e a diferença são percebidas como categorias centrais que, contrapondo-se à percepção moderna da identidade como uma essência, estável e fixa, traz no bojo do multiculturalismo a percepção identitária descentrada, múltipla e em processo permanente de construção e reconstrução.

Considerando a polissemia do termo multiculturalismo e suas diversas abordagens, autores como Canen (1999, 2001), Canen e Grant (1999), Canen e Moreira (2001) desenvolvem reflexões para além da valorização da diversidade cultural ao questionarem a própria construção das diferenças e, por conseguinte, dos estereótipos e preconceitos contra aqueles percebidos como "diferentes" no seio de sociedades desiguais e excludentes. No caso da educação e da formação de professores em sociedades multiculturais e desiguais como o Brasil, adotar o multiculturalismo como horizonte norteador significa aceitar desafios para o currículo que deve incorporá-lo nas normativas, nos discursos e nas práticas.

Inserida neste contexto sociocultural está a escola, que produz e/ou reproduz a exclusão de vários grupos sociais, gerando problemas, dentre os quais, o insucesso escolar e a evasão. 


\section{Multiculturalismo e seus significados}

Multiculturalismo se refere a uma pluralidade cultural que convive de forma harmônica, muito embora qualquer tentativa de defini-lo seja fracassada. Segundo Werneck (2008, p. 429) o multiculturalismo "pode consistir na justaposição ou presença de várias culturas em uma mesma sociedade e também na relação entre elas". O termo costuma ser utilizado em estudos antropológicos e sociológicos que pretendem explicar como as sociedades que possuem um acervo cultural tão diverso convivem entre si. A globalização, se quisermos identificar como um processo de inúmeras culturas que interagem entre si, produz um efeito na sociedade, dita globalizada, que é uma forte tendência para eliminar diferenças, promovendo uma cultura planetária.

Diretamente afetados, os sistemas educacionais, evidenciando a formação de novos imaginários sociais, são desprovidos de referentes históricos, geográficos e temporais, caracterizados por uma forte presença da cultura da imagem que traz reflexos na educação multicultural.

No passado, o multiculturalismo refletiu em diversas civilizações com seu próprio conjunto de manifestações culturais. Quando estas civilizações interagiam entre si aconteciam vários fenômenos gerando um processo que eliminava gradualmente as diferenças e gerava uma espécie de cultura comum ao incorporar muitos dos avanços e das características culturais de outros povos. Isso fez com que o multiculturalismo criasse uma espécie de cultura que reunia elementos variados.

Hoje, com a globalização, podemos observar como um processo semelhante acontece mediado pelas profundas transformações tecnológicas e econômicas possibilitando não somente que as distâncias se tornem cada vez menores como também aproximando diferentes culturas que antes eram esquecidas. Esta circunstância se refere ao multiculturalismo que, embora apresente muitas variantes culturais de povos com histórias diferentes, também produz um tipo de homogeneidade que acontece gradualmente e de forma constante.

Historicamente, o multiculturalismo surge nos Estados Unidos, em meio a conflitos e trocas entre dois grupos, a saber: o daqueles que se encontravam à margem da sociedade capitalista e o daqueles que se consideravam hegemônicos. Nesse contexto, cujo princípio ético buscava a orientação da ação de grupos culturalmente dominados, aos quais não foi garantido o direito de preservação de suas próprias características culturais, surgiu a concepção de multiculturalismo. 
O processo de democratização do ensino, que ocorreu a partir dos anos de 1980 no Brasil, apontava para a possibilidade de elaboração e implementação de reformas educacionais e prosseguiu aos anos de 1990, incorporando ao debate, a temática do multiculturalismo com teóricos da educação alertando para a importância da inserção da referida temática pela necessidade de tornar a educação menos desigual e, portanto, mais conhecedora das diferenças. Paralelamente, na década de 1990, vivenciou a ascensão e o fortalecimento de movimentos sociais que atuaram no campo multicultural e que, por infindáveis lutas, foram conquistando políticas educacionais relevantes.

Nesse período, a educação passou a ser compreendida como um espaço específico para abordagens contra discriminações de todos os tipos e o multiculturalismo, tratado na educação - mediante a falência da modernidade - pela crítica ao passado e ao abandono dos referenciais teóricos de análise da sociedade.

Homi BhaBha (1998) adverte que a harmonia só é alcançada em condições tácitas de normas sociais construídas e administradas pelo grupo dominante, obscurecendo-se o exercício do poder. Nessa perspectiva, o multiculturalismo encoraja o crescimento da tolerância, que é por definição, o reconhecimento simplificado do outro. Assim, segundo o autor, deve haver um multiculturalismo crítico (chamado de revolucionário, ou emancipatório, ou contra hegemônico) que, tendo por base a política cultural da diferença, evidencia as contradições socioculturais. Rejeitando o preconceito, esse multiculturalismo considera as interpretações e pontos de vista do outro possibilitando, assim transformações e criações culturais. Atualmente, a crítica à hegemonização cultural, à discriminação e ao racismo se dilui num discurso orientado por uma concepção estática de cultura e que se resgatado um entendimento dinâmico de cultura, esta deixa de ser um conjunto de características rígidas transmitidas de geração em geração para ser uma elaboração coletiva que se reconstrói a partir de denominadores interculturais.

Nesse horizonte de inquietações, o propósito de identificar práticas multiculturalmente comprometidas para analisar experiências pedagógicas imbuídas de questionamentos sobre a construção das diferenças focadas em dimensões identitárias específicas, tais como raça, etnia, religião, gênero e outras, propicia articular o processo de ensino-aprendizagem a posturas desafiadoras de preconceitos com relação às mesmas.

Assim, a perspectiva teórica de nossa análise dialoga com autores que têm investigado práticas pedagógicas efetivamente comprometidas com o multiculturalismo.

O conceito de hibridização (BHABHA, 1998; MCLAREN, 2000) constitui categoria para a compreensão do multiculturalismo em práticas comprometidas com essa perspectiva. 


\section{A prática pedagógica multicultural: uma prática discursiva e híbrida}

O multiculturalismo tem sido revisitado nos debates atuais pela necessidade de promover a equidade educacional, valorizar as culturas dos alunos e colaborar para superar o insucesso escolar. Romper preconceitos contra aqueles percebidos como “diferentes" é premente, uma vez que futuras gerações precisam ser educadas com novos valores em relação ao respeito e à apreciação à pluralidade cultural, além de serem provocadas em desafio a discursos preconceituosos que constroem as diferenças.

Entretanto, assim como ocorre com outros termos na área, o multiculturalismo apresenta uma polissemia (CANEN, 1999, 2000, 2001; CANEN; GRANT, 1999; CANEN; MOREIRA, 2001), englobando posturas epistemologicamente diversas e até mesmo conflitantes.

Há no cotidiano escolar uma concepção de multiculturalismo apenas como valorização da diversidade cultural, entendida de forma banalizada e folclórica, na qual sua significação é reduzida a um adorno no currículo escolar e, por conseguinte, o termo é usado e definido para comemoração de datas especiais. Silva (2000) ressalta a necessidade de discutir seus sentidos de forma mais engajada com posturas teórico-críticas de transformação social. É fato que valorizar a diversidade cultural, sem questionamento sobre diferenças e estereótipos, pouco contribui para a transformação de uma sociedade desigual como a que vivemos. Porém, é notório que o conhecimento de ritos, tradições e modos de pensar de variados grupos contribuem para valorizar a pluralidade cultural e desafiar preconceitos. Portanto, cabe à escola identificar mecanismos históricos, políticos e sociais pelos quais são construídos discursos que reforçam e silenciam identidades, bem como lutar pela superação destes mecanismos. Do contrário, o professor continuará desenvolvendo ações de trabalhador cultural ao invés de alguém que, com conhecimento cultural, busca transformar relações desiguais e entrecruzar fronteiras culturais tanto em seus discursos quanto em suas práticas. Nesse sentido, permanente nos discursos docentes, a ressignificação do discurso pedagógico nos conduz à hibridização discursiva. Segundo McLaren (2000), a possibilidade de construção de uma linguagem híbrida, ou seja, daquela que interpenetre as fronteiras culturais, incorpore discursos múltiplos, reconheça a pluralidade e a provisoriedade de tais discursos, implica numa reinterpretação das culturas que buscam promover sínteses interculturais criativas.

A linguagem híbrida procura superar os congelamentos identitários e as metáforas preconceituosas levando a uma "descolonização" dos discursos (BHABHA, 1998). No 
processo de hibridização, os marcos discursivos dominantes e colonialistas podem ser reapresentados e definidos como novos referenciais culturais, com base no contato com as culturas plurais. Compreender a mobilidade das identidades e seu caráter híbrido e transitório converge à promoção de práticas discursivas que contemplem uma linguagem também híbrida, configurada por estratégias discursivas constituídas por sínteses culturais criativas, singulares, locais e provisórias.

\section{O currículo crítico na perspectiva da multiculturalidade}

Partindo da discussão em que a hibridização da linguagem perpassa pelos múltiplos espaços sociais gerando novos saberes, cabe apresentar o conceito de currículo entendido por Moreira e Candau (2008), que contribui para entender a educação no contexto de interculturalidade como já definida. Sendo assim, os currículos são:

[...] as experiências escolares que se desdobram em torno do conhecimento, em meio a relações sociais, e que contribuem para a construção das identidades de nossos/as estudantes. Currículo associa-se, assim, ao conjunto de esforços pedagógicos desenvolvidos com intenções educativas. (MOREIRA; CANDAU, 2008, p. 18).

O entendimento apresentado acima desmistifica uma visão de o mesmo estar relacionado a plano ou lista de conteúdo que tem que ser cumprido para se chegar a um fim inexato, para introduzir uma visão de currículo que parte da análise da sociedade, do conhecimento cultural, das relações sociais que constroem esforços, via Projeto Políticopedagógico numa abordagem socioeducativa e multicultural.

Nesse contexto, o currículo se integra a fatores socioeconômicos, políticos e culturais que trazem marcas de um contexto em si, ampliando a reflexão sobre a função do mesmo nesse tempo em que se coloca a escola no verdadeiro espaço formador e facilitador do acesso do aluno ao conhecimento e a formação de sua identidade cultural. Se, segundo Silva (1999 apud MOREIRA; CANDAU, 2008, p. 17), a pós-modernidade traz reflexões sobre a visão do presente e não do futuro; sobre o conhecimento de forma relativa e não permanente, e o estado de consciência parcial e não total, tais características apontam para uma mudança de comportamento sobre o olhar do currículo que deixa de ser rotineiro e uniforme para assumir uma expectativa dinâmica e diversificada.

O currículo, dessa forma, atua numa dimensão crítica que articula saberes relacionados à cultura de mundo com a cultura escolar, integrando conhecimentos e não desprezando-os, pois todos os conhecimentos se unificam na formação do sujeito pensante. 
Perceber a criticidade desse currículo é entender sua contribuição diante do desafio de formar homens, cidadãos, conscientes de sua função de sujeito construtor da sociedade, tendo agora o conhecimento do espaço acadêmico um papel importante, pois, ao assumir sua ressignificação, segundo Moreira e Candau (2008, p. 21), possa, esse conhecimento ser "um dos elementos centrais do currículo e que sua aprendizagem constitui condição indispensável para que os conhecimentos socialmente produzidos possam ser apreendidos, criticados e reconstruídos por todos/as os/as estudantes do país".

Se a função do currículo é formadora, historicamente ficou presa à rigidez das doutrinas alienantes e estruturalistas da classe dominante que imperou, implantando currículos-empresa, campo, comércio, fábrica, indústria, entre outros, ficando imbricada à função de servir a um grupo de interesses.

Hoje, redefini-lo, significa colocá-lo diante dos desafios da sociedade com características de transformação social e humanizante, em que sujeitos aprendem na relação com o outro e com o mundo, o que para Arroyo (2011, p. 141) significa destruir esse "critério de racionalidade" do currículo para abrir espaço para os sujeitos críticos e autônomos, pois, diz o autor, "sem sua crítica não haverá lugar para sujeitos, continuarão mantidos no ocultamento.” (ARROYO, 2001, p. 141).

Esse ocultamento citado pelo autor demonstra a não participação social que deixa a classe dominante aparecer visualizando o sentido de um currículo de interesse, sem compromisso com o social, como Arroyo cita em sua obra, reproduzindo a fala das autoridades ao povo, "vocês sem saberes, sem cultura, venham aprender dos sábios e cultos." (ARROYO, 2011, p. 141). Esse discurso da escola tradicional apresentado pelo autor sobre o currículo, confirma a ideia de que o conhecimento escolar é suficiente para a formação de um currículo de vida que considera todas as relações sociais e, que portanto, somente a escola mantém o poder de ser formadora dele, sem ao menos questioná-lo.

No contexto atual, vê-se claramente uma política educacional de resultados, um currículo constituído de avaliações externas. Parece que os espaços educativos giram em torno de mostrar resultados - como publicações - para ocultar problemas. Como reflete Arroyo (2011.), esse ocultamento é uma forma de destruir o multiculturalismo, a participação social e contribuir para o fortalecimento das antigas relações de inferioridade, cultura nacional, exclusão social, violação dos Direitos Humanos.

Segundo Jallade (2000 apud LOPES, 2004, p. 111), “o currículo é o coração de um empreendimento educacional e nenhuma política ou reforma educacional pode ter sucesso se não colocar o currículo no seu centro". Essa citação revela que não adianta mudanças do 
ponto de vista político-estrutural ou financeiro apenas, para a educação, deve-se levar em conta a perspectiva crítico-social sobre currículo que de fato direcione seu olhar para as necessidades de mudança que a sociedade almeja alcançar para esse tempo de híbridos conceitos.

O conhecimento do cotidiano, nessa perspectiva, une-se ao conhecimento formal integrando-se numa proposta de autossustentação das ideias do ser que, diante do pensamento da pós-modernidade, abre espaço para a formação da identidade, ampliando as orientações das políticas curriculares que por muito se restringem às perspectivas homogeneizantes.

Dessa forma, o currículo assume uma nova forma de integração às problemáticas da sociedade e as discussões abrem espaço para temáticas culturais como gênero, sexo, etnia, credo, tecnologia, direitos humanos, educação ambiental e outras, que embora os PCN (BRASIL, 1998) já fizessem referência através dos temas Transversais, há uma necessidade de incorporá-las mais ainda enquanto prática, vivência e mudança de atitude, pois o currículo é um espaço de disputa em que a sociedade necessita do mesmo para debater novas concepções de convivência.

Mas, como iniciar essa discussão se não for pelas experiências do cotidiano que são trazidas pelos alunos à sala de aula? É inevitável. A universidade, através do seu Projeto Político-pedagógico encontra um campo perfeito para desenvolver estratégias que lidam com a junção de natureza do cotidiano com o conhecimento sistematizado. Portanto, o currículo, para assumir a função de formador, tendo que experimentar primeiro a exploração do cotidiano como conhecimento prévio, se quiser ser verdadeiro e honesto à realidade, caso contrário, continuará a reproduzir antigas práticas, como critica Arroyo (2011, p. 125): “os currículos e o material didático carregam um déficit de experiências e têm dificuldade de reconhecer ainda as experiências sociais, nem sequer dos educandos e dos educadores como conhecimento devido, sistematizado".

Contudo, para se definir esse currículo oficial, faz-se necessário debruçar o olhar sobre alguns elementos constitutivos que marcam a universidade: o primeiro é reconhecê-la como esfera de estudos culturais que, segundo Moreira e Silva (2011, p. 114), "nas duas últimas décadas gerou um forte interesse pelo conceito de 'cultura popular' e estimulou, consequentemente, uma série de importantes esforços para teorizar a ideia do "popular". Nessa perspectiva, a universidade assume a função de pesquisadora das culturas do povo, sem esquecer os aspectos global e local do contexto atual. 
O segundo elemento diz respeito a relacionar o currículo ao contexto de pósmodernidade, em que as questões atuais são refletidas no ambiente da universidade à luz da cidadania, da participação social e dos direitos humanos, no tempo e no espaço de relações interativas e midiáticas.

E por fim, o terceiro, o mais importante para um currículo na perspectiva da formação humana, que diz respeito a libertar as vozes ocultas, daí a importância da reflexão no curso da ação ou reflexão-em-ação e o prático reflexivo (SCHÖN, 1983) e a reflexão sobre o agir do professor (MACHADO, 2004) no contexto de sala de aula, para não reproduzir estereótipos já conhecidos. Nesse sentido é importante retomar o pensamento de Moita Lopes (2006, p. 103) quando diz: "contemplar as vozes do Sul”, que são silenciadas nas salas de aula ao ponto de reprimirem desejos, expectativas e sentimentos por conta de hegemonia ditatorial entre sociedade, família e universidade historicamente constituídas.

Libertar para que a universidade desoculte o currículo oculto gerador de bullying que dá impressão de uma sociedade perfeita, de brancos, de homens, de jovens, de católicos entre outros, em um campo em que as necessidades do aluno, integram-se a todos em um espaço sem homofobia, sem discriminação de qualquer tipo, sem racismo, transformando esse “'homem modulado', o mais notável produto da sociedade moderna” (BAUMAN, 2000, p. 161), - sem perfil, descontextualizado, repetitivo e programado para ser sem "essência" - em um ser das relações pessoais e das inter-redes.

Com esses três elementos relevantes para repensar o currículo, o conhecimento e a cultura nos espaços escolares, acredita-se que se estará contribuindo para composição de uma proposta curricular de função formadora "em que o multiculturalismo apela para o respeito à tolerância e a convivência pacífica entre as diferentes culturas" (SILVA, 2010, p. 86). Uma proposta curricular, portanto, que, no contexto das teorias pós-críticas do currículo, possa fortalecer a expectativa de uma cidadania plena, pensando os problemas da sociedade e colocando o estudante em formação inicial como protagonista de sua história.

\section{Considerações Finais}

O presente estudo buscou, nas considerações teóricas sobre o multiculturalismo, potencializar uma análise das formas possíveis de concretizar um currículo multicultural. Partindo da necessidade de problematização da temática e também da proliferação do debate envolvendo Multiculturalismo, Formação de Professores e Práticas Escolares, vimos diante de uma questão fulcral - a necessidade de pensar e elaborar orientações para o currículo 
híbrido seja por exigência ou por decisão permeada pela diversidade cultural - mas que não pode se submeter, nem enquanto política, nem enquanto implementação ou avaliação, a pressupostos de normatização externos ao contexto escolar.

Espera-se que essa provocação possa potencializar também a construção de práticas pedagógicas baseadas nos universos culturais dos alunos, hibridizando o discurso escolar com outros provenientes de campos diversos fundados no multiculturalismo e numa perspectiva das diferenças. Portanto, almejamos que uma prática pedagógica multicultural, aquela que se constrói discursivamente no desafio de reconhecimento das diferenças e dos preconceitos a ela relacionados, propicie uma formação de professores multiculturalmente comprometidos.

\section{Referências}

ARROYO, Miguel Gonzáles. Currículo, território em disputa. Petrópolis, RJ: Vozes, 2011.

BAUMAN, Zygmunt. Em busca da política. Tradução: Marcus Penchel. Rio de Janeiro: Zahar, 2000.

BHABHA, Homi K. O local da cultura. Belo Horizonte: Editora da UFMG, 1998.

BRASIL. Secretaria de Educação Fundamental. Parâmetros curriculares nacionais: terceiro e quarto ciclos: apresentação dos temas transversais. Brasília: MEC/SEF, 1998. Disponível em: < http://portal.mec.gov.br/seb/arquivos/pdf/ttransversais.pdf>. Acesso em: 22 nov. 2018.

CANEN, Ana. Universos culturais e representações docentes: subsídios para a formação de professores para a diversidade cultural. Educação e Sociedade, n. 77, p. 207-227, 2001.

CANEN, Ana. Educação multicultural, identidade nacional e pluralidade cultural: tensões e implicações curriculares. Cadernos de Pesquisa, n. 111, p. 135-150, 2000.

CANEN, Ana. Multiculturalismo e formação docente: experiências narradas. Educação e Realidade, v. 24, n. 2, p. 89-102, 1999. 
CANEN, Ana; GRANT, Nigel. Intercultural perspective and knowledge for equity in the Mercosul countries: limits and potentials in educational policies. Comparative Education, v. 35, n. 3, p. 319-330, 1999.

CANEN, Ana; MOREIRA, Antônio Flávio Barbosa. Reflexões sobre o multiculturalismo na escola e na formação docente. In: CANEN, Ana, MOREIRA, Antônio Flávio Barbosa (Org.). Énfases e omissões no currículo. São Paulo: Papirus, 2001. p. 15-43.

CANEN, Ana; OLIVEIRA, Ângela M. A. Multiculturalismo e currículo em ação: um estudo de caso. Revista Brasileira de Educação, Rio de Janeiro, n. 21, p. 61-74, 2002. Disponível em: < http://www.scielo.br/pdf/rbedu/n21/n21a05.pdf/>. Acesso em: 02 jun. 2018.

LOPES, Alice Casimiro. Políticas curriculares: continuidade ou mudança de rumos?. Revista Brasileira de Educação, Rio de Janeiro, n. 26, p. 109-118, ago. 2004. Disponível em: $<$ http://www.scielo.br/scielo.php?script=sci arttext\&pid=S141324782004000200009\&lng=en\&nrm=iso > . Acesso em: 02 jun. 2018.

MACHADO, Anna Raquel (Org.). O ensino como trabalho: uma abordagem discursiva. Londrina: Eduel, 2004.

MCLAREN, Peter. Multiculturalismo revolucionário: pedagogia do dissenso para o novo milênio. Porto Alegre: Artes Médicas, 2000.

MOITA LOPES, Luiz Paulo da. Linguística aplicada e vida contemporânea. In: MOITA LOPES, Luiz Paulo da. (Org.). Por uma linguística aplicada indisciplinar. São Paulo: Parábola Editorial, 2006.

MOREIRA, Antônio Flávio Barbosa; CANDAU, Vera Maria. Currículo, conhecimento e cultura. In: BEAUCHAMP, Jeanete; PAGEL, Sandra Denise. NASCIMENTO, Aricélia Ribeiro do. (Org.). Indagações sobre currículo. Brasília: Ministério da Educação, Secretaria de Educação Básica, 2008. 
MOREIRA, Antônio Flávio; SILVA, Tomaz Tadeu. (orgs.) Currículo, cultura e sociedade. 12. ed. São Paulo: Cortez, 2011.

SILVA, Tomaz Tadeu da. A produção social da identidade e da diferença. In: SILVA, T. T. da. (Org.). Identidade e diferença: a perspectiva dos estudos culturais. Petrópolis: Vozes, 2000. p. 73-102.

Documentos de identidade, uma introdução às teorias do curriculo. 3. ed. Belo Horizonte: Autêntica, 2010. 153 p.

SCHÖN, Donald Alan. The reflective practitioner. New York: Basic Book. 1983.

WERNECK, Vera Rudge. Uma avaliação sobre a relação multiculturalismo e educação. Ensaio: aval. Pol. Pub. Educ., Rio de Janeiro, v. 16, n. 60, p. 413-436, jul./set. 2008. Disponível em: <http://www.scielo.br/pdf/ensaio/v16n60/v16n60a06.pdf>. Acesso em: 03 jun. 2018.

recebido em 14 jun. 2018 / aprovado em 22 nov. 2018

Para referenciar este texto:

GUERRA, M. G. G. V.; CUSATI, I. C.; COSTA, K. F. Por um currículo plural na perspectiva do multiculturalismo. Dialogia, São Paulo, n. 30, p. 157-168, set. /dez. 2018. Disponível em: < https://doi.org/10.5585/Dialogia.n30.8798> 